\title{
ANALYSIS AND VERIFICATION OF THE OPERATION OF THE STABILIZING ROBUST CONTROLLER'S ELECTRICAL CIRCUIT OF THE ROTOR FLUX-LINKAGE CONTROL SYSTEM
}

On the basis of the classical theory of robust control, the theory of stability and the theory of continued fractions, the linearized mathematical model, the procedure for calculating and designing an analog electrical circuit of the $H \infty-$ suboptimal robust controller of the flux-linkage control system of the rotor of an asynchronous electric drive, protected by Ukrainian Patent no.137157, were built. The circuit contains three operational amplifiers, several resistors and capacitors. The proposed mathematical model, the procedure for calculating and choosing the parameters of the resistors and capacitors of the circuit take into account the random variations of the object and the controller within the specified boundaries. An analytical relationship between the transfer function coefficients and the resistances of the resistors and the capacitances of the capacitors of the controller's electrical circuit was established. On a specific example, by calculation according to the developed algorithm, the limiting values of the tolerances of the circuit's resistances of the resistors and capacitances of the capacitors were identified and these values were selected with a margin from the standard series. Analysis of noise filtering by the electrical circuit of the controller in the Multisim package shows its insensitivity to noise spreads within fairly wide boundaries. References 10, table 1, figures 4.

Key words: asynchronous electric drive, flux-linkage control system, robust controller, electrical circuit.

На базі класичної теорії робастного управління, теорії стійкості і теорії ланцюгових дробів побудовано лінеаризована математична модель, процедура розрахунку $i$ проектування аналогової електричної схеми Нळ-субоптимального робастного регулятора системи управління потокозчепленням ротора асинхронного електроприводу, що захищена патентом України № 137157. Схема містить три операційних підсилювача, кілька резисторів $i$ конденсаторів. Запропонована математична модель, процедура розрахунку $і$ вибору параметрів резисторів $i$ конденсаторів схеми враховують випадкові варіації об'єкта $i$ регулятора в заданих межсах. Встановлено аналітичний зв'язок між коефіцієнтами передавальної функцї̈ $і$ опорами резисторів $і$ ємностями конденсаторів електричної схеми регулятора. На конкретному прикладі розрахунковим иляхом за розробленим алгоритмом виявлені граничні значення допусків опорів резисторів і ємностей конденсаторів схеми $і$ здійснений їх вибір із запасом зі стандартних рядів. Аналіз фільтрації завад електричною схемою регулятора в пакеті Мицtisim показує ї̈ нечутливість до розмахів завад у досить широких межах. Бібл. 10, табл. 1, рис. 4.

Ключові слова: асинхронний електропривод, система управління потокозчепленням, робастний регулятор, електрична схема.

Introduction. In the patent [1], an analog electrical circuit of the $H_{\infty}$-suboptimal robust controller of the flux-linkage control system of the rotor of an asynchronous electric drive is proposed. Its design was carried out in the following sequence. First, a mathematical model of the control object was built and the transfer function of the controller was calculated, as in works [2-4]. Then this function was expanded into a continued fraction [4]. The coefficients of this fraction were used to construct a circuit diagram of the controller. This scheme is made in the form of an active quadripole. This quadripole contains nine resistors and three capacitors. The nominal values of such resistances and capacities of such elements are determined in this work in the process of rounding off their calculated values to the values of standard series [5], and their accuracy is based on the calculation of the stability of the rotor flux-linkage control system with random variations of the parameters of the object, resistors and capacitors of the circuit within the specified boundaries. At the same time, to set the boundaries of random change in the nominal values of resistances and capacitances, the rounding errors of their calculated values and the spread in the values of permissible deviations by standard series are taken into account. An unreasonable choice of these elements of a highprecision circuit can lead to a significant increase in its cost, and the choice of low accuracy - to a loss of efficiency. A compromise between cost and accuracy can be achieved theoretically only in the process of analyzing the stability of the flux-linkage control system with random variations of the nominal parameters of real circuit elements. However, such an analysis cannot be carried out without determining the analytical relationships between the coefficients of the transfer function of the controller and the parameters of the resistors and capacitors of the circuit, which vary randomly within the specified boundaries. Due to the linearity of the mathematical model of the robust fluxlinkage control system [4], such formulas cannot be obtained exactly [6,7]. Therefore, it is necessary to quickly check the operation of the circuit. It can be done in the interactive package Multisim. Such a check makes it possible to evaluate not only the operability of the designed circuit, but also the level of noise inhibition by this robust controller circuit [8].

The above approach allows solving the considered problem of analyzing and checking the operation of the electrical circuit of the controller. It was proposed by us

(C) I.N. Khlopenko, N.J. Khlopenko, S.A. Rozhkov 
in [4]. However, in this work, only the relationship between the coefficients of the transfer function of the controller and the parameters of its structural scheme was taken into account. Therefore, in this work, this relationship between the coefficients of the transfer function of the $H_{\infty}$-suboptimal robust controller and its electrical circuit is taken into account when analyzing and checking the operation of the circuit.

The aim of the work is to analyze and check the operation of the stabilizing $H_{\infty}$-suboptimal robust controller's electrical circuit of the rotor flux-linkage control system.

Research methods and results. Consider an undefined control object [4], consisting of a frequency converter and stator and rotor windings of an asynchronous electric motor. Represent the equations of its state in the normal operator matrix form (1):

$$
\begin{aligned}
& p x=A x+B u \\
& y=C x,
\end{aligned}
$$

where

$$
\begin{gathered}
A=\left[\begin{array}{ccc}
-\frac{1}{T_{2}} & \frac{L_{12} I_{\mathrm{n}}}{T_{2} \psi_{\mathrm{n}}} & 0 \\
0 & -\frac{1}{T_{1 \mathrm{eq}}} & \frac{E_{\mathrm{n}}}{R_{1 \mathrm{eq}} T_{1 \mathrm{eq}} I_{\mathrm{n}}} \\
0 & 0 & -\frac{1}{T_{\mathrm{fc}}}
\end{array}\right] \\
B=\left[\begin{array}{ccc}
0 & 0 & \frac{K_{\mathrm{fc}} U_{\mathrm{n}}}{T_{\mathrm{fc}} E_{\mathrm{n}}}
\end{array}\right]^{T} ; \quad C=\left[\begin{array}{lll}
1 & 0 & 0
\end{array}\right] ;
\end{gathered}
$$

where $p$ is the Laplace operator; $x=\left(x_{1}, x_{2}, x_{3}\right)^{T}$ is the phase vector, where $x_{1}=\Psi / \Psi_{\mathrm{n}} ; x_{2}=I / I_{\mathrm{n}} ; \mathrm{x}_{3}=E / E_{\mathrm{n}} ; \Psi$ is the rotor flux-linkage vector's module; $I$ is the current in the rotor flux-linkage channel; $E$ is the EMF of the frequency converter; $u=U / U_{\mathrm{n}}$ is the control action; $U$ is the controller output voltage; $y$ is the one-dimensional vector of the output, along which the feedback is closed; $T_{\mathrm{fc}}, K_{\mathrm{fc}}$ are the time constant and gain coefficient of the frequency converter; $T_{1 \text { eq }}=L_{\text {leq }} / R_{\text {leq }}$ is the electromagnetic time constant of the stator winding, where $R_{1 \mathrm{eq}}=R_{1}+\left(k_{\mathrm{r}}\right)^{2} R_{2}$ and $L_{\text {leq }}=\sigma L_{1}$ are its equivalent resistance and the leakage inductance; $R_{1}, R_{2}$ are the active resistances of the stator and rotor windings; $T_{2}=L_{2} / R_{2}$ is the electromagnetic time constant of the rotor winding; $L_{1}, L_{2}$ are the inductances of stator and rotor windings; $L_{12}$ is the mutual inductance of stator and rotor windings; $k_{\mathrm{r}}=L_{12} / L_{2} ; \sigma=1-\left(L_{12}\right)^{2} /\left(L_{1} L_{2}\right)$ is the coefficient of magnetic field scattering.

The extended system of equations [4] with uncertain parameters of the object $K_{\mathrm{fc}}, R_{1 \mathrm{eq}}, R_{2}, L_{1}, L_{2}$ and $L_{12}$ corresponding to Eq. (1) is represented in the form (2):

$$
\begin{aligned}
& p x=A x+B_{1} w+B_{2} u ; \\
& z=C_{1} x+D_{11} w+D_{12} u ; \\
& y=C_{2} x+D_{21} w+D_{22} u,
\end{aligned}
$$

where

$$
A=\left[\begin{array}{ccc}
-\frac{R_{2 \mathrm{n}}}{L_{2 \mathrm{n}}} & \frac{R_{2 \mathrm{n}}}{L_{2 \mathrm{n}}} & 0 \\
0 & -\frac{R_{\text {leqn }}}{L_{\text {leqn }}} & \frac{R_{\text {leq }}}{L_{\text {leqn }}} \\
0 & 0 & -\frac{1}{T_{\mathrm{fc}}}
\end{array}\right]
$$

$$
B_{1}=\left[\begin{array}{ccccccc}
0 & 0 & 0 & \frac{p_{R_{2}}}{L_{2 \mathrm{n}}} & \frac{p_{L_{12}}}{L_{2 \mathrm{n}}} & -p_{L_{2}} & -\frac{p_{R_{2}}}{L_{2 \mathrm{n}}} \\
0 & -p_{L_{\mathrm{leq}}} & -\frac{p_{R_{\mathrm{leq}}}}{L_{\text {leq } \mathrm{n}}} & 0 & 0 & 0 & 0 \\
\frac{p_{K_{\mathrm{fc}}}}{T_{\mathrm{fc}}} & 0 & 0 & 0 & 0 & 0 & 0
\end{array}\right] ;
$$

$$
\begin{aligned}
& C_{1}=\left[\begin{array}{ccc}
0 & 0 & 0 \\
0 & -\frac{R_{\text {leqn }}}{L_{1 \text { eqn }}} & \frac{R_{1 \text { eqn }}}{L_{1 \text { eqn }}} \\
0 & R_{1 \text { eqn }} & 0 \\
0 & R_{2 \mathrm{n}} & 0 \\
0 & R_{2 \mathrm{n}} & 0 \\
-\frac{R_{2 \mathrm{n}}}{L_{2 \mathrm{n}}} & \frac{R_{2 \mathrm{n}}}{L_{2 \mathrm{n}}} & 0 \\
R_{2 \mathrm{n}} & 0 & 0
\end{array}\right] ; \quad C_{2}=\left[\begin{array}{lll}
1 & 0 & 0
\end{array}\right] ; \\
& D_{11}=\left[\begin{array}{ccccccc}
0 & 0 & 0 & 0 & 0 & 0 & 0 \\
0 & -p_{L_{\text {leq }}} & -\frac{p_{R_{\text {leq }}}}{L_{\text {leqn }}} & 0 & 0 & 0 & 0 \\
0 & 0 & 0 & 0 & 0 & 0 & 0 \\
0 & 0 & 0 & 0 & 0 & 0 & 0 \\
0 & 0 & 0 & p_{R_{2}} & 0 & 0 & 0 \\
0 & 0 & 0 & \frac{p_{R_{2}}}{L_{2 \mathrm{n}}} & \frac{p_{L_{12}}}{L_{2 \mathrm{n}}} & -p_{L_{2}} & -\frac{p_{R_{2}}}{L_{2 \mathrm{n}}} \\
0 & 0 & 0 & 0 & 0 & 0 & 0
\end{array}\right] ;
\end{aligned}
$$

$$
\begin{gathered}
B_{2}^{T}=\left[\begin{array}{ccc}
0 & 0 & \frac{1}{T_{\mathrm{fc}}}
\end{array}\right] ; \quad D_{12}^{T}=\left[\begin{array}{lllllll}
1 & 0 & 0 & 0 & 0 & 0 & 0
\end{array}\right] \\
D_{21}=\left[\begin{array}{lllllll}
0 & 0 & 0 & 0 & 0 & 0 & 0
\end{array}\right] ; \quad D_{22}=[0] ;
\end{gathered}
$$

where $z=\left(z_{1}, z_{2}, \ldots, z_{7}\right)^{T}, w=\left(w_{1}, w_{2}, \ldots, w_{7}\right)^{T}$ are, respectively, the input and output uncertainty vectors interconnected by the matrix expression $w(p)=\Delta(p) \cdot z(p)$, in which the uncertainty matrix $\Delta(p)$ has a diagonal form.

The system of Eq. (2) is used to numerically determine the transfer function of the $H_{\infty}$-suboptimal controller using the mixed sensitivity method [9]. This transfer fractional-rational function for the nominal object has the form (3):

$$
K(p)=k \frac{p^{2}+b_{1} p+b_{2}}{a_{0} p^{3}+a_{1} p^{2}+a_{2} p+a_{3}},
$$

where $k, b_{1}, b_{2}, a_{0}, a_{1}, a_{2}, a_{3}$ are the some coefficients, the values of which are determined during the numerical solution of the problem.

The transfer function (3) vanishes at the point $p=\infty$. Therefore, it can be expanded by the Euclidean method into a continued fraction. Then, after multiplying the numerator and denominator of this fraction by a scale 
factor $\mu$, it can be represented in the vicinity of the point $p=\infty$ by a ladder RC function (4):

$$
\frac{k \mu}{c_{1} p+\frac{1}{r_{1}+\frac{1}{c_{2} p+\frac{1}{r_{2}+\frac{1}{c_{3} p+\frac{1}{r_{3}}}}}}},
$$

where $k_{\mu}=k \mu$.

As is known, the coefficients of this function correspond to the calculated values of the resistances $\left(r_{i}\right.$ values) of resistors and capacities ( $c_{i}$ values) of capacitors.

The relationship between the coefficients of the transfer function (3) and the ladder RC function (4) is determined in the process of folding the fraction (4) into a fractional rational expression and equating the coefficients of this expression with the corresponding coefficients of expression (3). As a result of such transformations, the following relations between them were found (5):

$$
\begin{aligned}
& b_{1}=\frac{1}{c_{2}}\left(\frac{1}{r_{2}}+\frac{1}{r_{1}}\right)+\frac{1}{c_{3}}\left(\frac{1}{r_{3}}+\frac{1}{r_{2}}\right) ; \\
& b_{2}=\frac{1}{c_{2} c_{3}}\left(\frac{1}{r_{2} r_{3}}+\frac{1}{r_{1} r_{3}}+\frac{1}{r_{1} r_{2}}\right) ; \quad a_{0}=\frac{c_{1}}{\mu} ; \\
& a_{1}=\frac{1}{\mu}\left(\frac{1}{r_{1}}+c_{1} b_{1}\right) ; \\
& a_{2}=\frac{1}{\mu}\left\{\frac{1}{r_{1}}\left[\frac{1}{c_{2} r_{2}}+\frac{1}{c_{3}}\left(\frac{1}{r_{3}}+\frac{1}{r_{2}}\right)\right]+c_{1} b_{2}\right\} ; \\
& a_{3}=\frac{1}{\mu c_{2} c_{3} r_{1} r_{2} r_{3}} ; \mu=c_{1 \mathrm{n}} .
\end{aligned}
$$

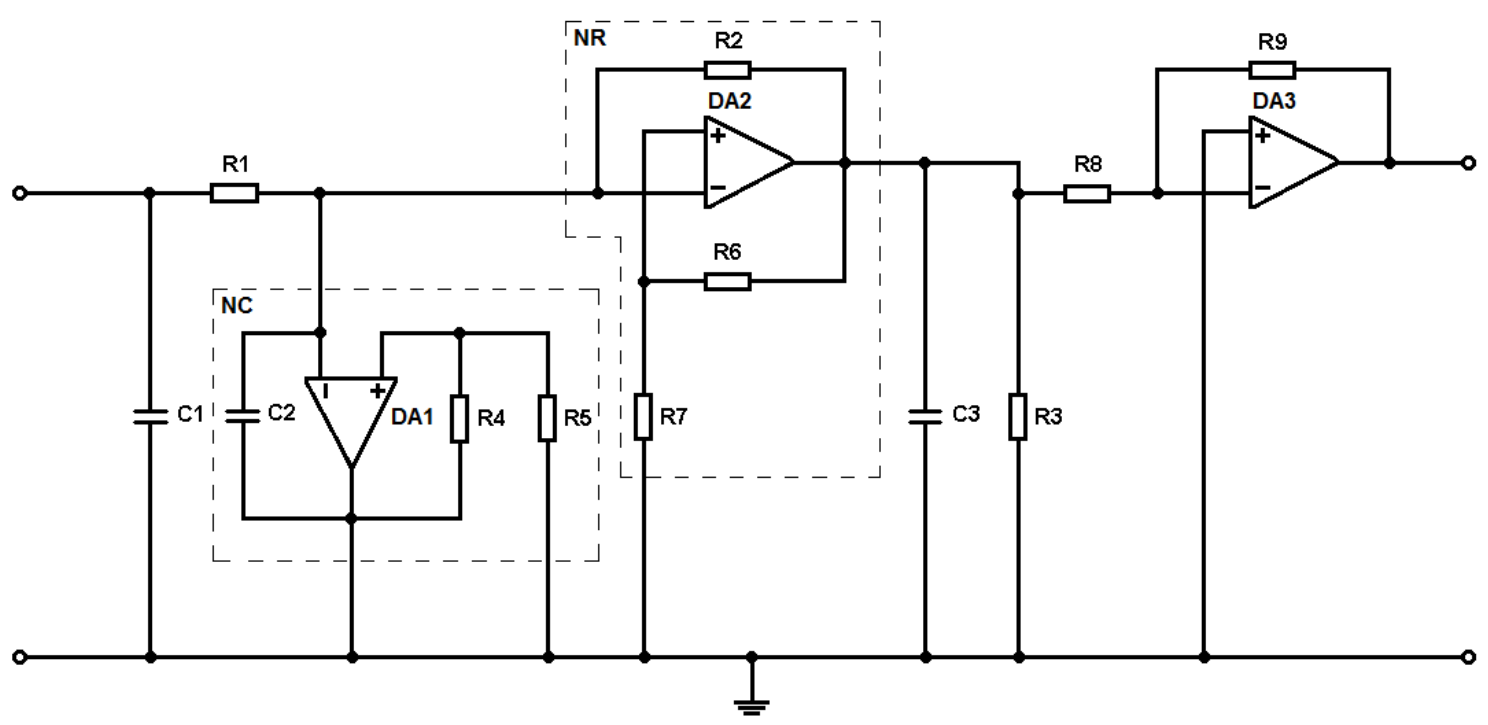

Fig. 1 Electrical circuit of a robust controller

The choice of the resistances of the resistors and capacitances of the capacitors of the electrical circuit is carried out in the process of rounding the calculated
To make relationship between the coefficients of the ladder circuit (4) with the resistances and capacitances of the electrical circuit of the robust controller, expressions (6) are used:

$$
\begin{aligned}
& c_{1}=C 1 ; \quad r_{1}=R 1 ; \quad c_{2}=C 2 ; \\
& r_{2}=R 2 ; \quad c_{3}=C 3 ; \quad r_{3}=R 3 ;
\end{aligned}
$$

where $R 1, R 2, R 3$ are resistances of resistors; $C 1, C 2, C 3$ are capacitances of capacitors.

If among the coefficients (6) of the ladder RC function there are negative capacitance $c_{i}$ with index $i$ and negative resistance $r_{k}$ with index $k$, then they are replaced by expressions of the form:

$$
c_{i}=-C_{i} \frac{R 4}{R 5} ; \quad r_{k}=-R_{k} \frac{R 6}{R 7} .
$$

Moreover, the indices in the right-hand sides of Eq. (7) denote the numbers of capacitors and resistances of the circuit according to Fig. $1 ; R 4=R 5$ and $R 6=R 7$; the fractions in Eq. (7) are irreducible, because the resistances of the circuit are selected with tolerances.

The written Eq. (7) with negative parameters of capacitance and resistance correspond to active circuits based on operational amplifiers studied in [10].

The relationship of the numerator $k_{\mu}$ of the ladder RC function (4) with the resistances $R 8$ and $R 9$ of the operational amplifier of the circuit is described by the equation (8):

$$
k_{\mu}=\frac{R 9}{R 8} .
$$

Relations (6) - (8) make it possible to construct a basic electrical circuit of the controller. This circuit for $i=k=2$ is shown in Fig. 1. It contains negatrons of negative capacitance $\mathrm{NC}$ and negative resistance NR, designed to suppress interference, and differs from circuit [1] only in other designations of resistance and capacitance indexes. values of the RC function coefficients (4) to the values of the standard series, and their permissible deviations are determined from the calculation of the stability of the 
robust rotor flux-linkage control system with random variations in the object parameters (1) and controller (4) within the specified boundaries. In this case, the resistances $R 4 \ldots R 7$ of the circuit resistors are selected from design considerations, and their accuracy from the same stability calculation.

The procedure for calculating and selecting the parameters of resistors and capacitors of the electrical circuit of a stabilizing robust rotor flux-linkage controller consists of the following sequence of actions:

1. The transfer function (3) of the controller of the nominal object is calculated.

2. The decomposition of the found transfer function into a continued fraction is performed and the ladder $\mathrm{RC}$ function (4) is compiled.

3. The coefficients of the ladder RC function (4) are rounded to the values of standard series [5].

4. The transfer function of the controller (3) is formed programmatically according to Eq. (5) - (8).

5 . The boundaries of the change in the nominal parameters of the object, the resistances of the resistors and capacitances of the capacitors of the electric circuit of the controller are set, taking into account the rounding error of their calculated values to the values of the standard series [5], as well as the accuracy of manufacture and cost.

6. A software system for the stabilization of the rotor flux-linkage consisting of the series-connected transfer functions of the controller (3) and the object (1), covered by a single feedback is made.

7. Curves of flux-linkage transient processes for a closed system and a Bode diagram for an open control system are calculated with random variations in the parameters of the object and the controller within the given boundaries.

8. The accuracy of stabilization of the flux-linkage is determined by the ranges of the curves of steady-state transient processes of the rotor flux-linkage, and by the Bode diagram the stability margins in amplitude and phase were determined.

9. The calculation according to items $5-8$ is repeated until a compromise in the choice of the controller's electrical circuit element's tolerances and their cost is achieved.

The calculations were performed at the following nominal values of the initial data of the object (1): $T_{\mathrm{fc}}=0,001 \mathrm{~s} ; R_{1 \mathrm{n}}=2,65 \Omega ; R_{2 \mathrm{n}}=2 \Omega ; L_{1 \mathrm{n}}=0,186 \mathrm{H}$; $L_{2 \mathrm{n}}=0,189 \mathrm{H} ; L_{12 \mathrm{n}}=0,179 \mathrm{H} ; \sigma=0,0996$, corresponding to an asynchronous electric drive with a MDXMA100-32 motor.

Calculated from these data, the nominal values of the parameters of the robust controller (3) turned out to be equal: $k=5,016 \cdot 10^{5} ; b_{1}=148,963 ; b_{2}=1,0612 \cdot 10^{4}$; $a_{0}=1 ; a_{1}=1,451 \cdot 10^{4} ; a_{2}=1,262 \cdot 10^{7} ; a_{3}=3,532 \cdot 10^{7}$. The calculated values of the resistances and capacitances of the ladder RC function (4) at $\mu=10^{-5}$ corresponding to these parameters were: $c_{1}=10 \mu \mathrm{F} ; r_{1}=6,963 \Omega$; $c_{2}=-197 \mu \mathrm{F} ; r_{2}=-5,709 \Omega ; c_{3}=12,56 \mathrm{mF} ; r_{3}=28,79 \Omega$. These values were rounded to the values of standard series [5]. These series, rounded values of quantities to the values of series, rounding errors and recommended tolerances of the series are shown in Table 1.

Table 1

Selection of resistances and capacitances of the circuit

\begin{tabular}{|c|c|c|c|c|c|}
\hline \multicolumn{2}{|c|}{ Designation } & \multirow{2}{*}{\begin{tabular}{|c|}
$\begin{array}{c}\text { A row } \\
\text { according to } \\
{[5]}\end{array}$ \\
E96
\end{tabular}} & \multirow{2}{*}{\begin{tabular}{|l|} 
Value \\
6,98 \\
\end{tabular}} & \multirow{2}{*}{$\begin{array}{c}\text { Rounding } \\
\text { error, \% }\end{array}$} & \multirow{2}{*}{$\begin{array}{c}\text { Recommended } \\
\text { row tolerance, \% }\end{array}$} \\
\hline R1 & \multirow{9}{*}{$\Omega$} & & & & \\
\hline R2 & & E96 & 5,69 & 0,33 & 2 \\
\hline R3 & & E24 & 30 & $-4,2$ & 5 \\
\hline R4 & & E24 & 100 & 0 & 5 \\
\hline R5 & & E24 & 100 & 0 & 5 \\
\hline R6 & & E96 & 100 & 0 & 2 \\
\hline R7 & & E96 & 100 & 0 & 2 \\
\hline R8 & & E24 & 100 & 0 & 5 \\
\hline R9 & & E24 & 510 & $-1,7$ & 5 \\
\hline $\mathrm{C} 1$ & \multirow{2}{*}{$\mu \mathrm{F}$} & E24 & 10 & 0 & 5 \\
\hline $\mathrm{C} 2$ & & E24 & 200 & $-1,5$ & 5 \\
\hline $\mathrm{C} 3$ & $\mathrm{mF}$ & E24 & 13 & $-3,5$ & 5 \\
\hline
\end{tabular}

The undefined parameters $K_{\mathrm{fc}} / K_{\mathrm{fc} \mathrm{n}}, R_{\text {leq }}, R_{2}, L_{1}, L_{2}$ and $L_{12}$ of the object (1) varied within the range of $\pm 90 \%$, the resistances $R 1, R 2, R 6, R 7$ - in the range of $\pm 3 \%$; $R 3, R 4, R 5, R 8, R 9$ and capacitance $C 1, C 2, C 3$ - in the range of $\pm 10 \%$. These errors of elements overlap the values of row tolerances recommended by [5] and other guiding documents approximately twice.

Fig. 2 shows 20 curves of the rotor flux-linkage transient processes corresponding to random variations of the undefined parameters of the object and the controller selected by the Monte Carlo method within the given boundaries. They are obtained in the MATLAB application packages with a single abrupt change in the reference action.

As seen, the curves of transient processes shown in Fig. 2 do not go beyond the boundaries of $3 \%$ tube.

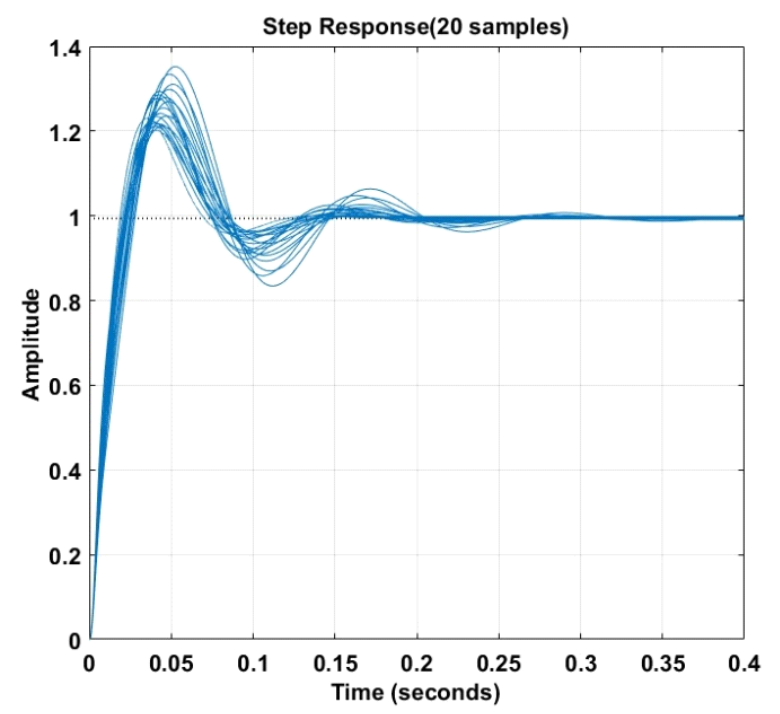

Fig. 2. Rotor flux-linkage transient processes

Fig. 3 shows a Bode diagram with 20 generated amplitude $L(\omega)$ curves and 20 phase $\varphi(\omega)$ frequency response curves with the same undefined parameters as in the previous case. From the amplitude $L(\omega)$ and phase 
$\varphi(\omega)$ characteristics presented in this diagram, it can be seen that the system is stable, since the amplitude characteristic crosses the abscissa axis earlier than the phase characteristic, finally falling off, going beyond the angle value of -180 degrees. In this case, the calculated values of the stability margin in amplitude is $19.2 \mathrm{~dB}$, and in phase is 50.6 degrees for the nominal values of the parameters of the object and the controller with scatter of random curves not exceeding $4 \mathrm{~dB}$ for amplitude and 15 degrees for phase frequency characteristics.

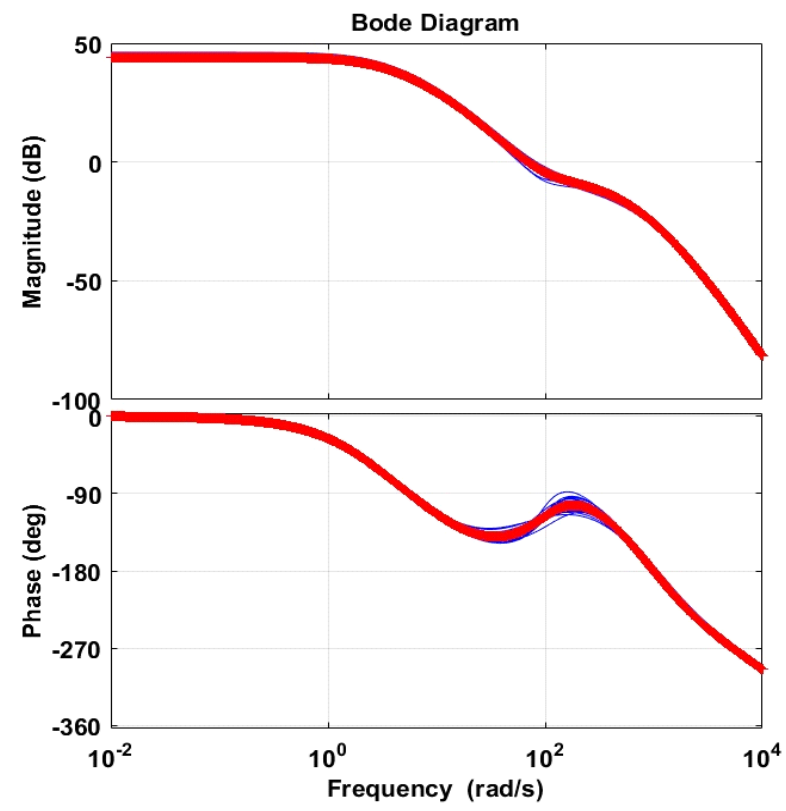

Fig. 3. Open-loop Bode diagram

Checking the operation of the circuit, which is shown in Fig. 1, was carried out in the Multisim package. Its modeling was carried out with random variations in the resistances of resistors and capacitances of capacitors of the specified accuracy. A constant voltage of $1 \mathrm{~V}$ and a harmonic signal with a frequency of $20,50,5000 \mathrm{~Hz}$ and an amplitude of $0.5 \mathrm{~V}$ were applied to the input of the circuit, which approximated the limit values of interference during the operation of the controller in the flux-linkage control system (for example, sensor noise, contacts in connectors, electromagnetic fields, interference with the frequency of the supply network, etc.). The voltage filtered by the controller was recorded at the output of the circuit. Recording of these voltages was carried out continuously with a multimeter (Fig. 4).

As expected, the electrical circuit of the $H_{\infty}$-suboptimal robust controller provides highprecision noise suppression. In this case, both with accurate and with rounded values of resistances and capacitances, the same voltage value of $11.8 \mathrm{~V}$ is set at the output, regardless of the frequency of the interference at the input. This voltage is approximately an order of magnitude less than the steady-state value calculated by Eq. (3) at $p=0$, because at the output from the circuit it is always determined with an accuracy to a constant factor.
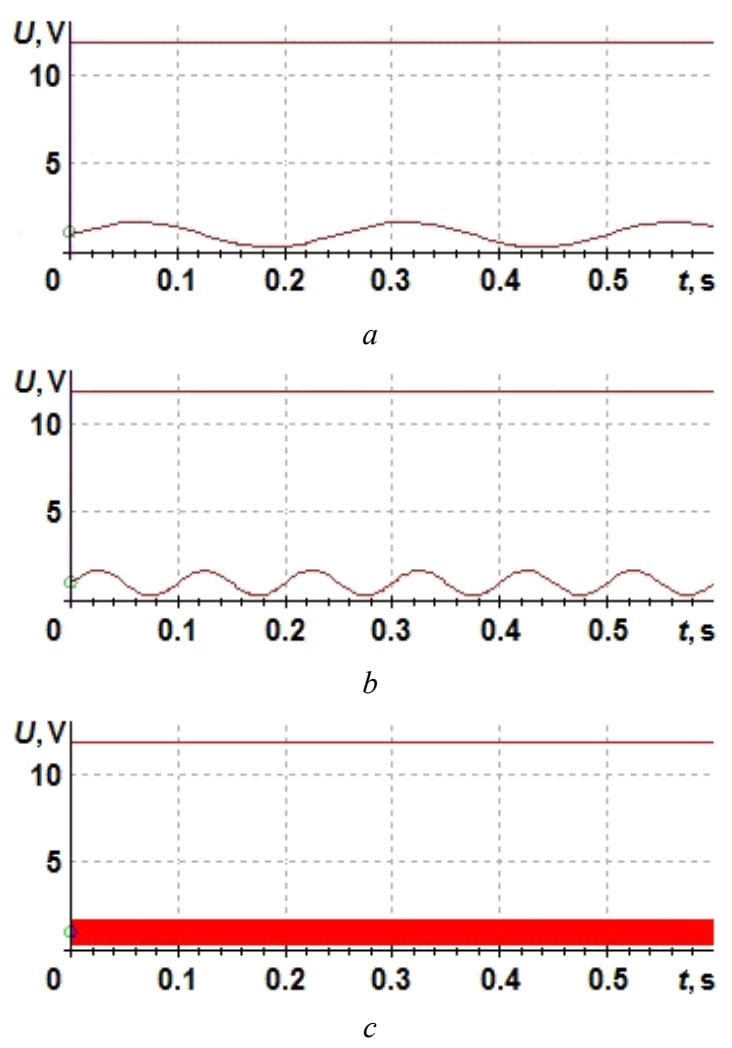

Fig. 4. Dependence of voltage $U$ at the input (sinusoidal line) and output (straight line) on time $t$ : $a-20 \mathrm{~Hz} ; b-50 \mathrm{~Hz} ; c-5000 \mathrm{~Hz}$

\section{Conclusions.}

1. For the first time, analytical dependences of the ladder RC function coefficients on the resistances of the resistors and capacitances of the capacitors of the $H_{\infty}$-suboptimal robust controller's circuit diagram were obtained, which allow, together with the control object within the ranges of the specified boundaries of the change in the undefined parameters of the object, the resistances and capacitances of the controller, to carry out calculations and analysis of stability of the stabilizing flux-linkage system and the selection on this basis of resistors and capacitors of the circuit from the series of preferred values, taking into account the margin of tolerances.

2. Based on the calculation and analysis of the stability of the robust flux-linkage control system and the obtained analytical expressions describing the relationship between the coefficients of the transfer function of the robust controller and the resistances of the resistors and capacitances of the capacitors of the electrical circuit of the controller, the limiting values of the tolerances for the selection of resistors and capacitors of the circuit from the preferred series, identified by a specific example.

3 . The analysis of the filtering of sinusoidal signals of various frequencies by the electric circuit of the regulator in the Multisim package carried out using the same example, taking into account the selected limit values of the tolerances of resistors and capacitors, shows its insensitivity to these signals. 


\section{REFERENCES}

1. Khlopenko N.Y., Rozhkov S.O., Khlopenko I.M. Sistema vektornogo keruvannya shvidkistyu asinhronnogo elektrodviguna [Asynchronous motor vector speed control system]. Patent UA, no. 137157, 2019. (Ukr).

2. Polilov E.V., Rudnev E.S., Skorik S.P. Synthesis of robust control algorithms for a synchronous electric motor means $H_{\infty}$-theory. Transactions of Kremenchuk Mykhaylo Ostrogradskiy State University, 2010, iss. 4/2010 (63), part 3, pp. 15-20. (Ukr).

3. Rudnev E.S., Morozov D.I. $\mu$-synthesis of robust speed controller of synchronous electric drives. Electrotechnic and Computer Systems, 2015, vol. 20, no. 96, pp. 42-50. (Rus). doi: 10.15276/eltecs.20.96.2015.06.

4. Khlopenko I.N., Rozhkov S.A., Khlopenko N.J. Stability and accuracy of the robust system for stabilizing the rotor flux-linkage of an asynchronous electric drive at random variations of the uncertain parameters within the specified boundaries. Electrical engineering \& electromechanics, 2018, no. 4, pp. 35-39. doi: 10.20998/2074-272X.2018.4.06.

5. GOST 28884-90. Riady predpochtitel'nykh znachenii dlia rezistorov $i$ kondensatorov [GOST 28884-90. Preferred number series for resistors and capacitors]. Moscow, Standartinform Publ., 2006. (Rus).

6. Kuznetsov B.I., Nikitina T.B., Kolomiets V.V., Bovdui I.V. Improving of electromechanical servo systems accuracy. Electrical engineering \& electromechanics, 2018, no. 6, pp. 33-37. doi: 10.20998/2074-272X.2018.6.04.
7. Kuznetsov B.I., Nikitina T.B., Bovdui I.V., Kobilyanskiy B.B. Improving of electromechanical stabilization systems accuracy. Electrical engineering \& electromechanics, 2019, no. 2, pp. 21-27. doi: 10.20998/2074-272X.2019.2.04.

8. Khlopenko N., Rozhkov S., Khlopenko I. Filtration Of Undesired Signals By The Robust Controller In The Rotor FluxLinkage Control System. Scientific Bulletin Kherson State Maritime Academy, 2019, vol. 1, no. 20, pp. 122-131. (Rus). doi: 10.33815/2313-4763.2019.1.20.122-131.

9. Richard Y., Chiang R., Michael G., Safonov M. MATLAB: Robust Control Toolbox. User's Guide. Version 2, 1998. 230 p. Available at: http://www.mathworks.com (Accessed 12 May 2016).

10. Petrenko I.A. Study of circuit negatrons properties, implemented on operational amplifiers. Technology audit and production reserves, 2016 , vol. 2 , no. 1 (28), pp. 40-50. doi: 10.15587/2312-8372.2016.66910.

Received 08.09.2020

Accepted 17.10.2020

Published 24.12.2020

I.N. Khlopenko ${ }^{1}$, Graduate Student,

N.J. Khlopenko ${ }^{1}$, Doctor of Technical Science, Professor,

S.A. Rozhkov ${ }^{1}$, Doctor of Technical Science, Professor,

${ }^{1}$ Kherson State Maritime Academy,

20, Ushakova Ave., Kherson, 73000, Ukraine.

e-mail: khlopenko.ivan@gmail.com,

khlopenko.n@gmail.com,

rozhkov_ser@meta.ua

How to cite this article:

Khlopenko I.N., Khlopenko N.J., Rozhkov S.A. Analysis and verification of the operation of the stabilizing robust controller's electrical circuit of the rotor flux-linkage control system. Electrical engineering \& electromechanics, 2020, no. 6, pp. 18-23. doi: 10.20998/2074-272X.2020.6.03. 